\title{
Value of Fluoroscopic Defecography in Constipated Children With Abnormal Colon Transit Time Test Results
}

\author{
Kyungmin Kim, ${ }^{1}$ Hae Jeong Jeon, ${ }^{2}$ and Sun-Hwan Bae ${ }^{3 *}$ \\ ${ }^{1}$ Department of Pediatrics, Konkuk University Medical Center, Seoul, Korea; and Departments of ${ }^{2}$ Radiology and ${ }^{3}$ Pediatrics, Konkuk University \\ Medical Center, Konkuk University School of Medicine, Seoul, Korea
}

\section{Background/Aims}

Colon transit time (CTT) test is regarded as the gold standard for evaluating colon transit function. Fluoroscopic defecography (FD) is a dynamic radiologic test to assess anorectal function. The aim is to evaluate the value of FD in constipated children with abnormal CTT test results.

\section{Methods}

Fifty-one children (27 girls) with a mean age of $9.8 \pm 3.2$ years who met Rome III criteria for constipation and older than 5 years with abnormal CTT test results underwent FD.

\section{Results}

Of 51 children, 27 (52.9\%) showed positive findings on FD, including pelvic floor dyssynergia (PFD) (10/27, 37.0\%), structural abnormality $(15 / 27,55.6 \%)$ (rectocele $53.3 \%$, intussusception 33.3\%, and both 13.4\%), and both PFD and rectocele (2/27, 7.4\%). In terms of CTT test subtype, of 35 children who had outlet obstruction type in CTT test, 19 (54.2\%) had positive findings, including PFD (8/19, 42.1\%), structural abnormality (9/19, 47.4\%) (rectocele 55.6\%, intussusception 22.2\%, and both $22.2 \%$ ), and both PFD and rectocele $(2 / 19,10.5 \%)$. Of the 16 children who had slow transit type of CTT test, $8(50.0 \%)$ had positive findings, including PFD $(2 / 8,25.0 \%)$ and structural abnormality $(6 / 8,75.0 \%)$. Of the 6 children who had structural abnormality, $3(50.0 \%)$ had rectocele and $3(50.0 \%)$ had intussusception. For the 2 children $(2 / 16,12.5 \%)$ who had PFD, puborectalis muscle relax failure was found on FD. Puborectalis muscle relax failure was treated with biofeedback and medication. In the minor abnormalities, medication continued without additional therapeutic modalities.

\section{Conclusions}

FD was valuable for both diagnoses of underlying causes and interpretation of CTT test results in children with abnormal CTT test results. Therefore, this study suggests that FD and CTT tests should be incorporated into logical thinking for constipation in children.

(J Neurogastroenterol Motil 2020;26:128-132)

\section{Key Words}

Child; Constipation; Defecography; Fluoroscopy; Ororectal transit

Received: December 3, 2018 Revised: February 12, 2019 Accepted: August 7, 2019

(.) This is an Open Access article distributed under the terms of the Creative Commons Attribution Non-Commercial License (http://creativecommons. org/licenses/by-nc/4.0) which permits unrestricted non-commercial use, distribution, and reproduction in any medium, provided the original work is properly cited.

${ }^{*}$ Correspondence: Sun-Hwan Bae, MD Department of Pediatrics, Konkuk University Medical Center, Konkuk University School of Medicine, 120-1 Neungdong-ro, Gwangjin-gu, Seoul 05030, Korea Tel: +82-2-2030-7554, Fax: +82-2-2030-7748, E-mail: baedori@hanafos.com 


\section{Introduction}

Constipation is one of the most common digestive disorders in childhood. Its incidence is $3-10 \%$ of visits to general pediatric clinics, accounting for $20-25 \%$ of referrals to pediatric gastroenterologists worldwide. ${ }^{1,2}$ However, its significance is underestimated. In general, proper treatment is far from reality.

A colon transit time (CTT) test using radiopaque markers is regarded as the gold standard for evaluating colon transit function in both adults and children. Functional constipation can be classified into normal colon transit type, outlet obstruction type, and slow transit type based on the CTT test. This classification may be helpful for establishing an accurate diagnosis and effective treatment both in children and adults. ${ }^{3-5}$ The value of CTT test for prognosis in children has been proven. Prolonged CTT test value implies poor clinical status, and constipation accompanying encopresis shows prolonged CTT test values compared to those without encopresis. $^{6-8}$

Fluoroscopic defecography (FD) is a dynamic radiologic test performed during the voluntary evacuation of the rectum to assess anorectal function, including pelvic floor and puborectalis muscle at rest and during defecation. By using $\mathrm{FD}$, various pelvic disorders such as paradoxical puborectalis contraction syndrome, rectocele, intussusception, and perineal descent can be easily diagnosed. Previous studies in adults have shown that FD is of value for evaluation of outlet obstruction. ${ }^{9,10}$ However, FD study in children with constipation is very rare. ${ }^{11,12}$ The aim of this study is to evaluate the value of $\mathrm{FD}$ for the diagnosis of underlying causes or interpretation of CTT test results in constipated children.

\section{Materials and Methods}

\section{Patients}

About 500 children who met the Rome III criteria for constipation at the Department of Pediatrics, Konkuk University Medical Center in Seoul between August 2005 and December 2016 underwent colonic transit time tests. Among them, 51 subjects with abnormal CTT test results (using protocol from Metcalf et $\mathrm{al}^{13}$ ) and older than 5 years underwent FD. This study was approved by the Institutional Review Board of Konkuk University Medical Center (IRB No. KUMC 2019-11-018).

\section{Fluoroscopic Defecography}

Before FD, rectal emptying was carried out with bisacodyl rectal suppository (Dulcolax rectal suppository; Boehringer-Ingelheim Korea, Seoul, Korea). The examination began, while the child was in the left decubitus position, by injecting a stool-like, semisolid barium paste (Solotop solution; Taejoon Pharmacy, Seoul, Korea) into the rectum and distal sigmoid colon until the child felt an urge for defecation from rectal distension. After then, the child sat upright on a specialized radiolucent commode. Spot radiographs of the anorectal region were performed at rest, during squeezing, and during straining (Valsalva maneuver) in the lateral projection. Cine images were performed during defecation (expulsion of barium paste). ${ }^{12}$

\section{Radiological Analysis and Criteria for Diagnosis}

Tests were performed under the direction of radiologists and images were analyzed by 30 year-experienced Gastroenterology radiologists. Normal study of FD included the following: (1) opening of the anorectal angle (ARA) on attempted evacuation and increase in ARA; (2) loss of puborectalis impression; (3) perpendicular descent of the anorectal junction below the pubococcygeal line at maximal evacuation; (4) shortening of the anal canal; (5) absence of intussusception or rectocele or rectal prolapse; and (6) contraction of the rectum. The ARA was defined as the angle between the anal canal longitudinal axis and the posterior rectal line parallel to the longitudinal axis of the rectum. It was measured during rest and straining. In the resting condition, its average value was $95^{\circ}-96^{\circ}$ (physiological range, $\left.65^{\circ}-100^{\circ}\right)$. ARA is an indirect indicator of puborectalis muscle activity. The degree of pelvic floor descent was defined as the perpendicular distance from the anorectal junction to the pubococcygeal line, the line joining the superior anterior angle of the pubic symphysis to the tip of the coccyx on lateral pelvic radiography. Rectal intussusception is a circumferential descent of the entire thickness of the rectal wall. It might extend into the anal canal, but not through the anal verge. Rectal prolapse is a circumferential descent of the entire thickness of the rectal wall seen coming out through the anal verge. Rectocele is an out-pocketing of the anterior rectal and posterior vaginal wall into the lumen of the vagina. Plevic floor dyssynergia (PFD) is characterized by the failure of pelvic floor muscles to relax or a paradoxical contraction of the pelvic floor muscles, which leads to an absence of change or paradoxical decrease in ARA, resulting in pelvic outlet obstruction. Defecographic evidence of a dyskinetic puborectalis includes a persistent posterior indentation of the puborectalis muscle, lack of perineal descent, a lack of straightening of the rectoanal angle, and poor opening of the anal canal. ${ }^{9,11,14}$ 
Table 1. Demographic Characteristics of Patients (Boys and Girls) in Each Age Category

\begin{tabular}{lccc}
\hline \multicolumn{1}{c}{ Age } & $\begin{array}{c}\text { Boys } \\
(\mathrm{n}=24)\end{array}$ & $\begin{array}{c}\text { Girls } \\
(\mathrm{n}=27)\end{array}$ & $\begin{array}{c}\text { Total } \\
(\mathrm{N}=51)\end{array}$ \\
\hline Toddlers (5-6 yr) & 3 & 1 & 4 \\
Elementary school (7-12 yr) & 18 & 17 & 35 \\
Adolescents (13-18 yr) & 3 & 9 & 12 \\
Mean age (yr) & $9.4 \pm 2.8$ & $10.1 \pm 3.5$ & $9.8 \pm 3.2$ \\
\hline
\end{tabular}

Data are presented as $n$ or mean $\pm \mathrm{SD}$.

Table 2. Fluoroscopic Defecography Results of 51 Patients

\begin{tabular}{lc}
\hline \multicolumn{1}{c}{ Findings on Defecography } & $\mathrm{n}(\%)$ \\
\hline Normal & $24(47.1)$ \\
Abnormal & $27(52.9)$ \\
Pelvic floor dyssynergia & $10(37.0)$ \\
Structural abnormality & $15(55.6)$ \\
Rectocele & $8(53.3)$ \\
Intussusception & $5(33.3)$ \\
Rectocele + intussusception & $2(13.4)$ \\
Pelvic floor dyssynergia + rectocele & $2(7.4)$ \\
Total & $51(100.0)$ \\
\hline
\end{tabular}

\section{Results}

\section{Patient and Clinical Features}

This study enrolled 51 children, 24 boys and 27 girls, and the mean age was $9.8 \pm 3.2$ years (5-18 years). Demographic features of the children are summarized in Table 1. On CTT test, 35 (68.6\%) had outlet obstruction type while $16(31.4 \%)$ had slow transit type.

\section{Fluoroscopic Defecography Results}

Of 51 children, 27 (52.9\%) showed positive findings on FD, including PFD (10/27, 37.0\%), structural abnormality (15/27, $55.6 \%)$, and both PFD and rectocele (2/27, 7.4\%). Structural abnormality included rectocele $(8 / 15,53.3 \%)$, intussusception $(5 / 15$, $33.3 \%)$, and both $(2 / 15,13.4 \%)$ (Table 2$)$.

In terms of CTT test subtype, for those $(\mathrm{n}=35)$ with outlet obstruction type of CTT test, positive findings were detected in 19 (54.2\%), including PFD (8/19, 42.1\%), structural abnormality $(9 / 19,47.4 \%)$, and both PFD and rectocele (2/19, 10.5\%). Structural abnormality included rectocele $(5 / 9,55.6 \%)$, intussusception $(2 / 9,22.2 \%)$, and both $(2 / 9,22.2 \%)$. For those $(n=16)$ with slow transit type of CTT test, positive findings were detected in 8 (50\%), including $\operatorname{PFD}(2 / 8,25.0 \%)$ and structural abnormality $(6 / 8$,
Table 3. Fluoroscopic Defecography Results According to Colon Transit Time Type in 27 Patients

\begin{tabular}{lcc}
\hline CTT & $\begin{array}{c}\text { Outlet ob- } \\
\text { struction type } \\
(\mathrm{n}=35)\end{array}$ & $\begin{array}{c}\text { Slow transit } \\
\text { type } \\
(\mathrm{n}=16)\end{array}$ \\
\hline Pelvic floor dyssynergia & $8(42.1)$ & $2(25.0)$ \\
Structural abnormality & $9(47.4)$ & $6(75.0)$ \\
$\quad$ Rectocele & $5(55.6)$ & $3(50.0)$ \\
$\quad$ Intussusception & $2(22.2)$ & $3(50.0)$ \\
$\quad$ Rectocele + intussusception & $2(22.2)$ & $0(0.0)$ \\
Pelvic floor dyssynergia + rectocele & $2(10.5)$ & $0(0.0)$ \\
Total & $19(100.0)$ & $8(100.0)$ \\
\hline
\end{tabular}

Data are presented as n (\%).

$75.0 \%)$. In terms of structural abnormality, rectocele was found in $3 / 6(50.0 \%)$ and intussusception was found in 3/6 (50.0\%) (Table 3).

In 2/16 (12.5\%) children with slow transit type on CTT test, puborectalis muscle relax failure was found on FD.

\section{Discussion}

In this study, FD was performed in a logical flow with abnormal CTT test result as an essential prerequisite. This study showed that more than half of constipated children with abnormal CTT test results had positive findings on FD. In addition, more than $10.0 \%$ of abnormal CTT test results were corrected based on FD.

To evaluate pelvic floor and anorectal function, several diagnostic tests could be applied, including high resolution anorectal manometry with balloon expulsion, FD, and magnetic resonance imaging defecography. These diagnostic modalities can dynamically evaluate the process of defecation. Considering co-operation of young children, accessibility to sitting position magnetic resonance imaging defecography and defecation physiology, FD could be the first dynamic method that can visually evaluate the process of defecation in children. Despite the risk of radiation exposure, FD is particularly useful for functional and real-time assessment of the mechanics of defecation in a physiologic setting. Because of its ability, FD has been useful in working up patients with longstanding or refractory constipation or with unexplained anal or rectal pain., ${ }^{9,10}$ In a previous study with FD, 18 children with defecation problems (chronic constipation, fecal incontinence, rectal prolapse) and normal anorectal manometry were enrolled without choice. PFD was detected in $50.0 \%(\mathrm{n}=9)$ while structural abnormality was found in $22.0 \%(\mathrm{n}=4) .^{12}$ In another study, FD was performed 
as an initial screening test in constipated children. ${ }^{11}$ In the present study which enrolled 51 children with abnormal CTT test results, positive findings were detected in $52.0 \%(\mathrm{n}=27)$ of the children. Structural abnormalities including rectocele and intussusception were detected in $55.0 \%$. PFD was detected in $37.0 \%$ while both PFD and structural abnormalities were detected in $7.0 \%$. This was a surprising result that we did not anticipate. It guided us to proper treatment.

Unlike previous studies, this study performed a CTT test to screen for patients undergoing FD. Subtype classification of constipation based on CTT test may be helpful for establishing an accurate diagnosis and effective treatment. CTT test results also have prognosis value for children. Therefore, in our center, CTT test is performed as one of the basic tests whenever possible. In terms of CTT test results, positive finding rates on FD were about the same for outlet obstruction type (54.2\%) and slow transit type (50.0\%). For the outlet obstruction type, PFD (42.0\%) and structural abnormality (47.0\%) were about the same. However, in slow transit type, structural abnormality (75.0\%) was more prominent than PFD (25.0\%). PFD is a slow transit type that needs special attention. In this study, in more than $10.0 \%$ of children with slow transit type on the CTT test, puborectalis muscle relax failure was found on FD. Considering these results, we usually recommend FD in children with abnormal CTT test results if the child is more than 5 years old, to obtain correct underlying causes.

Interestingly, among the 12 children with rectocele in the FD test, the male to female ratio was 2:10. They had constipation for 5 years or more on average, two patients who had puborectalis relax failure improved with biofeedback as well as medication. Patients with minor structural defects continued medical treatment.

On radiation dose control, the effective dose equivalent considered as an expression of total patient risk for radiation exposure to limited areas of the body is significantly lower for FD (3-7 millisievert $[\mathrm{mSv}])$ than that for barium enema studies $(10-17 \mathrm{mSv})$ in adults. ${ }^{15,16}$ In a previous study with children, radiation dose of FD was measured one-third to one-half of barium enema study in children. ${ }^{17}$ Although the area exposed to the beam is smaller in FD, more radiation per unit area is used. Therefore, local dose is higher with FD. Consequently, ovarian dose that is important owing to genetic risk for severe hereditary effects is slightly higher for FD compared with barium enema. ${ }^{16,18}$ Considering this, the procedure is usually performed within 1-2 minutes and strict inclusion criteria are applied for the test in our center, especially for girl patients.

The limitation of this study is that children younger than 5 years were not enrolled in this study, because we thought they could not cooperate with the procedure.

In conclusion, FD performed in constipated children with abnormal CTT test can detect various structural and functional findings in more than half of cases. These findings can guide directions of further diagnosis or treatment. In addition, CTT test results could be corrected based on results of FD. FD and CTT tests should be incorporated into logical thinking for constipation in children.

\section{Financial support: None.}

\section{Conflicts of interest: None.}

Author contributions: Kyungmin Kim and Sun Whan Bae were responsible for data collection and drafting the manuscript; and Kyungmin Kim, Hae Jeong Jeon, and Sun Whan Bae were responsible for study conception, data-analysis, and interpretation.

\section{References}

1. Loening-Baucke V. Chronic constipation in children. Gastroenterology 1993;105:1557-1564.

2. Mugie SM, Di Lorenzo C, Benninga MA. Constipation in childhood. Nat Rev Gastroenterol Hepatol 2011;8:502-511.

3. Kim ER, Rhee PL. How to interpret a functional or motility test-colon transit study. J Neurogastroenterol Motil 2012;18:94-99.

4. Bae SH KM. Subtype classification of chronic functional childhood constipation with colon transit time test: therapeutic perspective 5th World Congress of Pediatric Gastroenterology Hepatology and Nutrition. Montreal, Canada, 2016: Poter 318.

5. Lembo AJ US. Constipation. In: Feldman M, Frediman LS, Brandt LJ, eds. Sleisenger and Fordtran's gastrointestinal and liver disease. 9th ed. Philadelphia: Saunders Elservier Co. 2010:259-284.

6. de Lorijn F, van Wijk MP, Reitsma JB, van Ginkel R, Taminiau JA, Benninga MA. Prognosis of constipation: clinical factors and colonic transit time. Arch Dis Child 2004;89:723-727.

7. Benninga MA, Büller HA, Tytgat GN, Akkermans LM, Bossuyt PM, Taminiau JA. Colonic transit time in constipated children: does pediatric slow-transit constipation exist? J Pediatr Gastroenterol Nutr 1996;23:241251.

8. Yoo HY, Kim MR, Park HW, Son JS, Bae SH. Colon transit time test in Korean children with chronic functional constipation. Pediatr Gastroenterol Hepatol Nutr 2016;19:38-43.

9. Mellgren A, Bremmer S, Johansson C, et al. Defecography. Results of investigations in 2,816 patients. Dis Colon Rectum 1994;37:1133-1141.

10. Harvey CJ, Halligan S, Bartram CI, Hollings N, Sahdev A, Kingston K. Evacuation proctography: a prospective study of diagnostic and therapeutic effects. Radiology 1999;211:223-227.

11. Zhang SC, Wang WL, Liu X. Defecography used as a screening entry 
for identifying evacuatory pelvic floor disorders in childhood constipation. Clin Imaging 2014;38:115-121.

12. Mugie SM, Bates DG, Punati JB, Benninga MA, Di Lorenzo C, Mousa HM. The value of fluoroscopic defecography in the diagnostic and therapeutic management of defecation disorders in children. Pediatr Radiol 2015;45:173-180.

13. Metcalf AM, Phillips SF, Zinsmeister AR, MacCarty RL, Beart RW, Wolff BG. Simplified assessment of segmental colonic transit. Gastroenterology 1987;92:40-47.

14. Faccioli N, Comai A, Mainardi P, Perandini S, Moore F, PozziMucelli R. Defecography: a practical approach. Diagn Interv Radiol
2010;16:209-216.

15. Rannikko S, Servomaa A, Ermakov I, et al. Calculation of the estimated collective effective dose equivalent (SE) due to x-ray diagnostic examinations--estimate of the SE in Finland. Health Phys 1987;53:31-36.

16. Goei R, Kemerink G. Radiation dose in defecography. Radiology 1990;176:137-139.

17. Jorge JM, Habr-Gama A, Wexner SD. Clinical applications and techniques of cinedefecography. Am J Surg 2001;182:93-101.

18. Shrimpton PC, Wall BF, Jones DG, et al. Doses to patients from routine diagnostic x-ray examinations in England. Br J Radiol 1986;59:749-758. 